\title{
Attribution and contestation: Relations between elites and other social groups
}

Tijo Salverda and Irene Skovgaard-Smith

\begin{abstract}
In this article we explore the often ambiguous relations between elites and other social groups, both subordinate and of relatively equal standing. The article draws on two distinctive ethnographic cases: the white Franco-Mauritian elite, and the expert elite of management consultants in a Western European context. Our analysis of the two cases provides insights into how the power and status of elites is both contested and attributed by the people they interact with and relate to in concrete, yet substantially different contexts and situations. The aim is to show how the position and power of different kinds of elites is relationally negotiated and achieved. As we argue, a better understanding of the role of other social groups in the attribution, maintenance and contestation of status is relevant for understanding both more traditional economic elites and expert elites without tight networks.
\end{abstract}

\section{Keywords:}

Elites, power, agency, post-colonial, consultants, Mauritius, Denmark

\section{Reference:}

Salverda, T. and Skovgaard-Smith, I. (forthcoming) Attribution and contestation: Relations between elites and other social groups. Critique of Anthropology 


\section{Introduction}

Questions about power and inequality have long played a prominent role in anthropology. In an insightful overview, Ortner (2016: 49) refers to this as dark anthropology: 'anthropology that emphasises the harsh and brutal dimension of human experience, and the structural and historical conditions that produce them'. Notwithstanding the many relevant theoretical insights that have emerged out of the engagement with these concerns, one end of the power spectrum receives relatively less ethnographic attention in these analyses: the powerful end, which is where elites are positioned. They certainly feature prominently in the theory, yet often in rather abstract forms. This is not to suggest that many anthropologists are not aware of the nuances involved when we have shared our observations with colleagues we have found them to be highly conscious of such issues. However, apart from a number of significant studies that have demonstrated the complexities of the power and position of elite groups (e.g. Cohen, 1981; Ho, 2009; Marcus, 1983; Shore and Nugent, 2002; Ouroussoff, 2010; Wedel, 2009; Werbner, 2004), a nuanced understanding of powerful actors remains relatively absent in the theoretical literature despite Nader's (1972) plea, more than forty years ago, for anthropologists to 'study up'. Accordingly, we may not fully grasp the intricacies of power and inequality.

In this article we will look more closely at the often ambiguous relations between elites and other social groups. We will draw on two distinctive cases: a traditional elite group, namely the white former colonial elite of the island of Mauritius; and a non-traditional expert elite, specifically management consultants. Comparing these may seem arbitrary at first sight. Yet, as we show, despite the differences there are relevant similarities that contribute to a better understanding of elites and power more widely. Both illustrate that (1) sentiments towards elites fluctuate between resentment, contestation, respect, and attribution. Thus, at the same time as elite status and power is open to challenge and contestation, elite status is also attributed to particular categories of social actors. This latter issue especially tends to be less understood. In addition, the cases illustrate that (2) to understand the position of elites we must not only take into account relations between elites and subordinate groups, but also look at elites' relations with groups of relatively equal standing.

\section{Case overview}

The Franco-Mauritians are a long-standing elite with control over economic assets. Their position is constituted within the national context of Mauritius and has been substantially contested since the end of the colonial period in 1968. From 2005 onwards, the first author has conducted 
extensive research on how the Franco-Mauritians have maintained their elite position in the transition from the colonial period to the present (e.g. Salverda, 2015). More than 130 interviews were conducted with Franco-Mauritians, and over 30 interviews with other Mauritians; in addition, a network analysis of Franco-Mauritian business networks, a questionnaire (with FrancoMauritians), media analysis, participant observation and informal conversations with many more Mauritians and Franco-Mauritians provided rich data.

In the absence of a native population, the Franco-Mauritians relatively easily laid the foundations of their elite position during the French period, from 1715 till 1810 (Ly-Tio-Fane Pineo, 1993; Vaughan, 2005). Subsequently, their control over large parts of the island's land helped them to maintain their elite position throughout the British period, from 1810 until Mauritius gained its independence in 1968. When the British departed from the island, Mauritian society had a very diverse population, including descendants of the colonisers, of slaves and of indentured labourers. Nowadays, the island has about 1.3 million inhabitants and is strongly divided along ethnic lines. Most Hindus (approximately 52\% of the population) and Muslims (approximately 16\%) descend from indentured labourers that came from India to work on the predominantly Franco-Mauritian-owned sugar plantations. Due to their numbers, Hindus have become the dominant political force in postcolonial Mauritius. Creoles (about 28\%) are a mixed group, including many who descend from the island's slave population that worked the plantations prior to the abolition of slavery in 1835 . The majority of them share the same Catholic faith, as do most Franco-Mauritians (about 1\% of the population), although many of the former group belong to the poorest section of the population. In addition, there is a small group of SinoMauritians (about 3\%), who descend from Chinese migrants that settled on the island (Eriksen, 1998).

With the end of the colonial period, the position of the Franco-Mauritians has changed substantially. They have lost their political position, and their elite status is nowadays much more contested. Yet they have remained the island's dominant economic group. As a result many Mauritians express resentment towards the Franco-Mauritians and associate them with the legacy of colonial inequality and injustices. In a reflective mood, one Franco-Mauritian businessman said:

... we are perceived as rich and this perception does not imply that it is [an] incorrect [one]. In a way we set the standard and other communities don't like that; and what is the lowest job Franco-Mauritians have? Salesman? There are not many secretaries. Other communities don't like it that the Franco-Mauritians are always the bosses. 
Simultaneously, however, Mauritians also attribute status to the Franco-Mauritians and often confirm their position at the top of the island's socio-economic hierarchy. To explain the maintenance of the Franco-Mauritian elite position, then, the often paradoxical and ambiguous relations between Mauritians and Franco-Mauritians need to be considered.

Management consultants, in contrast to Franco-Mauritians, constitute a knowledge elite that has relatively recently obtained elite status. Their position is not associated with historical embedded social hierarchies, landownership and colonial injustices, and they do not share as strong a sense of belonging as the Franco-Mauritians. Instead it is their mastery of expert knowledge based on dominant economic and managerial ideologies and ideas of meritocracy that functions as a foundation for power and stratification (Zald and Lounsbury, 2010).

The analytical starting point in the study of management consultants conducted by the second author was the aim to understand how their elite status is constructed in their everyday interactions with people in client organisations, i.e. in a much more confined micro setting than in the case of the Franco-Mauritians. To this end, the second author conducted fieldwork amongst management consultants in Denmark as they worked on projects to improve the efficiency of internal operations in two client organisations - a public hospital, and a manufacturing company (e.g. Skovgaard-Smith, 2008). The fieldwork involved observation of consultants in situations such as meetings and workshops, as well as informal conversations and interviews with involved actors - both the consultants and members of the client organisations at various levels. In total 54 interviews were conducted across the two organisational sites.

The modern form of management consulting first emerged in America in the 1930s, and the profession has since enjoyed rapid growth in size and scope, becoming deeply embedded in developed economies and exerting an enormous influence on corporate, public and third-sector organisations that use their expensive advisory services (McKenna, 2006). A key source of the elite status of management consultants is their mastery of new forms of knowledge, broadly defined as management ideas and solutions to managerial problems in organisations based on what Weber (1976) called technical rationality and the logic of rationalisation and economic efficiency. Analytical skills and mathematical-logical intelligence are other key signifiers, along with highly selective recruitment practices that provide the profession with 'a touch of intellectual elitism' (Armbrüster, 2004: 1259). As the two consulting firms represented in the study state on their website, they recruit only 'the best and the brightest'. 
Accordingly management consultants 'tend to believe that they are a chosen elite and belong to a collective of special individuals' (Kärreman and Alvesson, 2009: 1128) who are intelligent, innovative, progressive, and leading-edge (Alvesson and Robertson, 2006; Alvesson and Empson, 2008). High pay and bonus packages, impressive buildings and distinctive locations (Alvesson and Robertson, 2006) further serve as tangible and material manifestations of privilege, exclusivity and economic wealth in much the same way as they do for financial elites such as investment bankers. During fieldwork the consultants implicitly emphasised their status symbols such as expensive cars by making the anthropologist's little red Volkswagen Polo from 1989 the target of much friendly banter.

Another marker of distinction is the cultivation of mystique and opaqueness which, as Shore (2002) argues, is part of what characterises economic, corporate, military and political elites who routinely restrict access to their activities. Reactions to the study indicated this. The business media found it intriguing that an anthropologist had gained access to and was able to observe consultants in action. An article about the research project in a Danish business newspaper was titled: 'Consultants under the magnifying glass' (Tholstrup, 2005) and the anthropologist conducting the research was portrayed as being on a fascinating expedition into the unknown and mysterious world of consultants. Various agents of public discourse also perform the cultivation of mystique, as consultants are the butt of jokes but also portrayed as 'great men' with the power to save and ruin businesses (Craig, 2005; Kihn, 2005; O'Shea and Madigan, 1997).

Though the two cases are substantially different in form, history and operations, by comparing them we aim to offer a more fine-grained understanding of the roles of other social groups in the maintenance of elite status. Analysing the everyday realities of elites operating in very different settings is, in our opinion, relevant for understanding both more traditional elites and elite groups without tight networks, often operating beyond national contexts (e.g. Hay, 2013; Mizruchi, 2013), and who rely on less traditional resources, such as expert knowledge (e.g. Zald and Loundsbury, 2010). Before we will explore by whom, in what situations and for what purposes elite positions are constructed, contested, maintained and attributed in the two cases, we will start with a theoretical discussion in order to elucidate how our analysis builds upon, and contributes to, existing theories. After the discussion of the empirical cases, we will end the article with a comparative discussion and conclusion. 


\section{The formation and maintenance of elite status}

What constitutes an elite, and who can be said to occupy the most influential positions in important spheres of social life (Shore, 2002), are increasingly complex questions in the context of highly diversified societies characterised by division of labour, occupational specialisation and separate fields of activity and expertise. Thus the identification of elites tends to be a contextual issue (Harvey, 2002), and qualifying terms such as political elites, economic elites, intellectual elites, knowledge or expert elites, academic elites, bureaucratic elites, military elites, etc. are used to distinguish various forms of elite (e.g. Khan, 2012; Watson, 2002).

Although the formation and maintenance of elite status is the result of a complex interplay of social processes (Lamont et al., 2014), the most tangible and central element determining the position of elites tends to be their control over resources (e.g. Scott, 2008; Woods, 1998). Without the unequal distribution of resources there would be little need to analyse elites and inequality. In particular, material resources such as the means of production, financial capital, and land feature prominently in analyses of elites and inequality (e.g. Marx, 2007). Yet equally of relevance are parliamentary control (e.g. Dogan and Higley, 1998) and non-material resources such as cultural capital and intellectual knowledge (e.g. Bourdieu, 1984; Dogan, 2003). More recently, though this is not a completely new tendency, attention is devoted to non-material sources such as celebrity status (e.g. Milner, 2015) and varieties of expert knowledge (e.g. Zald and Lounsbury, 2010).

To maintain control over resources, one of the main features of elites is to keep the size of the group small, because diffusion does not facilitate control over resources. Cohen (1981) illustrates that elites need to share a number of characteristics that fosters cohesion, and distinguishes elite groups from other social groups - the elites' particularistic tendencies. This is especially facilitated by educational institutes (e.g. Bourdieu and Clough, 1996; Khan, 2011), private clubs (e.g. Pinçon and Pinçon-Charlot, 1998), boardrooms (e.g. Davis, Yoo and Baker, 2003; Heemskerk and Fennema, 2009), and exclusive holiday destinations (e.g. Cousin and Chauvin, 2013) - in other words, a shared way of life or habitus (Bourdieu, 1994) and tight networks (e.g. Mills, 2000).

Equally of relevance in shaping exclusivity and distinction are signs of superiority and status symbols (e.g. Bourdieu 1994; Daloz 2007, 2010). They range from physical appearance, dominance in a particular professional domain, land ownership and wealth (such as in the case of the white Franco-Mauritians) to high earnings, access to the executive suites and boardrooms of companies, highly selective recruitment practices, and the cultivation of managerial expertise and knowledge mystique as in the case of management consultants. As a result of the elite's aim to maintain 
exclusivity and keep non-elites at bay, non-elites interact with these symbols and signs of superiority, as we show in this article. On the one hand, symbols of distinction may catalyse nonelites' resentment towards elites' unequal position of power. On the other hand, non-elites may also attribute power to elites through the ways in which the former approach elite symbols. In the case of emulating symbols, be they material or non-material, non-elites thus confirm the status of elites. Whether symbols are perceived with resentment or awe, the approach and behaviour of other social groups - of various kinds and statuses - towards elites and their symbols of distinction opens up wider questions about the relationships between elites and other social groups. The latter are often presented as passive bystanders who have little influence on the perpetuation of socio-economic hierarchies. This runs the risk of obscuring the roles played by the public, wider social norms and beliefs, and other social groups in the maintenance of social hierarchies.

\section{Contestation and attribution}

In this article our starting point is that elite status cannot be taken for granted or assumed, and we similarly cannot rely solely on the self-representation of any elite. Instead we have to explore the mutually constituting processes of differentiation that produce distinctions and status differences, and investigate what social purposes these distinctions further (see also Skovgaard-Smith, 2013). Such cultural processes involve both dominant and other actors in the mutual and relational mobilisation of shared categories and classification systems (Lamont et al., 2014). For example, the combination of dominant beliefs about capitalism and meritocracy has led to wide acceptance that people should be financially rewarded for success, even when this leads to rampant inequality and may simultaneously be the result of rent-seeking instead of meritocracy. As Zald and Lounsbury (2010: 964) critically remark, '... economists still wield great influence despite many examples that illustrate that they do not know what they are doing'. Accordingly, we take a critical approach towards perceptions that non-elites are only subdued by elites - through, for example, symbolic violence (Bourdieu and Passeron, 1990), hegemony (Gramsci, 1971), dominant discourse (Foucault, 1972), or false consciousness (Engels, 1968). We do not deny elites' potential to pacify and/or violently suppress non-elites. Yet we consider the allocation of agency problematic. Elites are frequently presented as the only ones with agency in relations with other social groups, while these groups are portrayed as being virtually exempted from having agency. Accordingly, existing theory 'underestimates the ability of non-elites to mobilize and bring about change', while the power of elites is often overstated (Milner, 2015: 8). 
As many (historical) examples illustrate, elites cannot take their position for granted. In contrast to widespread beliefs that elites are all-powerful, John Scott (2008: 38) argues, 'power is intrinsically tied to the possibility of resistance, and the power of the elite must be seen as open to challenge from the resisting counteraction of its subalterns' (see also Salverda, 2010). That other social groups oppose and contest elites indicates that the former often have more agency than commonly assumed. Conversely, when other social groups do not challenge elites, or even attribute qualities to them as we show in this article, this may equally result from the exercising of agency - in this case in a non-confrontational manner. Indeed, as James Scott (1976: 160) argues, when subordinates 'accept' existing hierarchies this does not necessarily result from false consciousness and an inability to see that they are being subdued. They also posses agency to accept principles that may reinforce the position of elites - while simultaneously they may reject and/or undermine other principles (Scott, 1976: 239; see also Scott, 1985). The absence of confrontation, then, is not necessarily the result of hegemony. Moreover, on the other end of the spectrum, the elites' agency is not necessarily unbounded. They may benefit most from certain dominant beliefs, yet they do not necessarily have control over social beliefs, and may also have to conform to them. As Mauss (1972: 40) similarly argues with regard to the status and power of magicians, '[i]t is public opinion which makes the magician and creates the power he wields'. Equally, the political elites in France are expected to behave with grandeur while at the same time they cannot behave with too much of an air of superiority and disdain (Daloz 2008). This connects with Cohen's (1981) argument that elites need some sort of support from other social groups more generally. He refers to this as the elite's universalistic tendencies, i.e. the need to promote its service to the public. When elites fail to find a good balance between their universalistic tendencies and the previously explained particularistic tendencies, it may lead to their demise. They may, for example, organise themselves very well, but when they fail to obtain much-needed support from other social groups their position can become precarious. What these studies explore less, however, is how elite status is attributed to elites by others in the interactions. Additionally, such studies mainly pay attention to elites' relations with subordinate groups, and not to relations with other elite groups of relatively similar standing. As our empirical analyses in the following sections illustrate, the contestation and attribution of power and status to elites should be understood as also resulting from the interactions between widespread (cultural) beliefs and the agency of both elite groups and other social groups. 


\section{The Franco-Mauritian case study}

When asked about the Franco-Mauritians, many Mauritians are quick to express their resentment. Memories about the historical injustices and the legacy of the past still evoke bitterness.

Expressing a wider sentiment about Franco-Mauritian privileges and preferential treatment, a Sino-Mauritian said that Franco-Mauritians are born with a golden spoon in their mouths. In addition, he said, 'they have an arrogant sense of superiority. They still have a colonial mentality.'

The symbolic aspect of their skin colour has come to serve the channelling of resentment particularly well, because almost fifty years after Mauritian independence physical appearance remains an important marker of distinction and status. Franco-Mauritians' white skin colour, moreover, continues to facilitate their access to and control over resources (Salverda, 2011). As a result, numerous Mauritians have memories of rejection. A gens de couleur woman, a member of the elite stratum of the Creole community, and with a variety of forms of mixed black and white ancestry, remembered how a group she was with was refused to enter a whites-only yacht club in the north of the island. They were a mixed group of Franco-Mauritians and gens de couleur, and one of the latter was considered to be too black to enter (the woman herself had a fairly pale skin). As a result of these kinds of experiences, her view of the Franco-Mauritian community was rather negative. Yet she expressed her resentment mainly in private. Due to the precarious balance between the different ethnic groups in postcolonial Mauritius, most Mauritians refrain from expressing opinions about the role of ethnicity too openly. In some instances, moreover, Mauritians may also fear the consequences of openly criticising Franco-Mauritians. A former head teacher of one of the Franco-Mauritian-frequented private schools explained that some of the teachers would not dare to voice too much criticism towards Franco-Mauritian parents. They would be afraid of compromising the positions of their partners working for Franco-Mauritianowned businesses.

The position of Franco-Mauritians is also openly contested, however, in particular within the context of national politics. Politicians often use rhetoric about the white Franco-Mauritians to mobilise support, due to the latters' association with the perpetuation of economic power, racism and injustices perpetrated in the past. As a result of these contestations, Franco-Mauritians have adopted a low profile in the political domain. Apart from the Franco-Mauritian politician Paul Bérenger (who is an outlier in many ways, and as such his rich political career is unique, rather than exemplary of the wider Franco-Mauritian community) most Franco-Mauritians refrain from engaging in politics. Bérenger's case actually serves as a reminder of the risks involved in voicing a political opinion. Although Bérenger has been a highly regarded politician for much of the 
postcolonial period and has never been a proponent of Franco-Mauritian interests, his political opponents frequently associate him with white privilege in order to discredit him. Also, politicians of other ethnic backgrounds have to walk a fine line and avoid being associated with FrancoMauritian economic power. There is much to lose and little to gain, as few Mauritians are willing to defend the Franco-Mauritians publically. Even when they are sceptical of politics and are of the opinion that politicians often have ulterior motives, most will not openly support the FrancoMauritians.

Franco-Mauritians are certainly aware of resentment expressed towards them in the political domain, yet they seem not to fully grasp the resentment among other Mauritians. Reflecting on the question of how he thinks Mauritians perceive Franco-Mauritians, a FrancoMauritian CEO of one of the largest family-holdings said, 'in everyday life you don't notice a lot of resentment ... I think that there is a lot of esteem for the moral standards of the FrancoMauritians. We're considered honest, with the right manners, and courageous'. He acknowledged that this was a guess, and that a little survey in the street might help to capture what other Mauritians think of Franco-Mauritians. Though his remark confirms that Franco-Mauritian selfperception is certainly overly positive, it does not come completely out of thin air.

\section{Reluctant attribution}

In the case of the Franco-Mauritians the attribution may be less overt, as in the case of the consultants as we discuss below, though not absent. While resentment is often more overt, the ascription of the Franco-Mauritian elite position appears more intangible. The expression of respect, for example, seems to often occur in everyday interactions and without the actors being fully aware of it. A Franco-Mauritian explained how he sometimes felt a bit awkward when entering a shop and being attended to first when there were non-white Mauritians in line in front of him. Equally, many domestic workers would confirm their Franco-Mauritian employers' superior position in their everyday interactions with them - this is probably similar in the case of domestic workers of other elite and upper middle class Mauritians, though with the significant difference that skin colour does not enter the equation in a similar way.

Owing to the maintenance of Franco-Mauritian privileges, whiteness continues to be perceived as something equating to economic power. A non-white Catholic priest said, 'white is considered fine and black is considered dirty'. Through processes such as self-identification or selfstigmatisation, subordinates often participate in the confirmation of social hierarchies as much as dominant agents (Lamont et al., 2014: 583). White Franco-Mauritians, as a result, are attributed 
more power and respect than non-whites. Similarly, in Martinique a black boss badly treating a black worker was considered worse than a white boss doing the same (Kovats Beaudoux and Giraud, 2002: 171).

The role, of other Mauritians is relevant, then, because apart from the more abstract 'white-bashing' in the political domain there are hardly any confrontations in daily life. Mauritians' behaviour towards the Franco-Mauritians in everyday interactions may convey a more subordinate message and contribute to the attribution of an elite position. Indeed, a FrancoMauritian informant said:

It was clear that as a white you were privileged. Even now people will treat me respectfully. And Indian man would say monsieur to a white, even to a twelve-year-old boy. This is not specifically the Indians, but also the Creoles ... Having white friends is perceived as social climbing, because the whites have always been considered the elite.

In addition to the psychological legacy of the white skin colour, Franco-Mauritians are also praised for their business and management skills, the quality of their products and service, and their contribution to the island's development. A former editor-in-chief of one of the island's newspaper said, 'I have to give the Franco-Mauritians credit. They invest almost everything in Mauritius. They only have some real estate outside the country. In Mauritius, they take the risk'. Equally, Franco-Mauritians are acknowledged for their sense of community and solidarity. As a result of common beliefs about ethnicity, many Mauritians consider intra-ethnic homogeneity and solidarity as virtues (Eisenlohr, 2006). Thus at the same time as expressing resentment, and despite the overlap between ethnicity and the perpetuation of inequality, Mauritians perceive Franco-Mauritians as an example of how to organise kinship relations. Dominant cultural beliefs, in this case about ethnicity, are not necessarily concocted by elites but may nevertheless contribute favourably to the maintenance of their position. Yet even in the case of praise Mauritians are often ambiguous and aware of the sensitivities involved. For example, at the same time as a gens de couleur woman was expressing her admiration for the Franco-Mauritians, she was also wondering whether she was not being too positive about them.

The result of the attribution of power and status by other social groups is that an elite position may entail more than would be assumed solely on the basis of the resources an elite controls. The Franco-Mauritian elite position does not rely on their economic privileges alone, but also on the outcomes of their relationships with other Mauritians. A Franco-Mauritian working for 
a local NGO further illustrated this. He said that when he wants to speak to a minister he uses the advantage of his Franco-Mauritian background. To make it past the gatekeeper, the minister's secretary, he would stress his Franco-Mauritian name. Due to the association of this name with power the secretary would be more accommodating and connect him with the minister directly, he said - which would not have happened would he not have conveyed the message that he was a Franco-Mauritian. Elites, in other words, are (un)consciously influenced by the way they feel others treat them, as well as by how symbols of distinction are interpreted by others.

\section{The management consultant case study}

The extent to which elite status was attributed to consultants as they interacted with client actors in the two organisations was striking. In contrast to the case of the Franco-Mauritian elite where attribution is more implicit and taken for granted, executives and other management staff in the client organisations explicitly and continuously worked to distinguish the consultants, setting them apart in interaction and constructing them as superior in various ways. Managerial elites in both organisations, such as executives, expected the consultants to know the answers to questions they did not know themselves. The following situation in a meeting between two consultants and the top management team of the manufacturing company can serve as an example. The CEO had been with the company for a couple of years and had originally been headhunted to save the company by the investment fund that had bought it on the brink of bankruptcy. As the consultants presented their analysis of the problems they had identified and started sketching out some suggestions for possible solutions, the CEO urged, 'Just say what we should do. Tell us what it is going to take for it to really make a difference'. The CEO expected the consultants to know what he, with all his experience in executive positions, did not know. This indicates that consultants are attributed with a particular form of elite status based on perceived superior expertise - in this case by a corporate executive who belongs to the managerial elite.

In interviews with managers and staff at different levels, in both the manufacturing company and the hospital, a key repertoire for differentiating the consultants was the perception that they posses state-of-the art knowledge and expertise that enables them to provide new ideas and solutions to problems in organisations, as we saw in the above situation where the CEO pushed for the consultants to provide just such information. Here is how another executive in the manufacturing company described one of the consultants: 
John is an extremely skilled expert within production and logistics and flows and stock and optimisation on distribution and Lean [a management philosophy/concept] and all that. There he really outperforms everyone here in the company, right.

As both the elite management layer and other lower-level managers in the two organisations expressed it, the consultants are expected to possess particular forms of management knowledge that are superior and advanced. A project manager in the hospital for instance described the consultants working there in a similar way:

They have some knowledge that no one has here, or that any of us have at this point. So just professionally we would not be able to do what they do. You know, because we don't know that way of thinking and things like that, so we have to have someone with the expertise, right.

Negation plays an important role in how this differentiation is achieved, and this is not limited to the repertoire of superior expertise. Consultants can also make people 'see'. As a head nurse, also a lower-level manager in the hospital, described it:

You see it in a different way all of a sudden - oh yeah, that is actually true. Sometimes you can be there having done things where they then come and say: 'well why like this and why like that? Why don't you do it like this instead?' And you realise, oh yeah, that is a lot easier.

Organisational members are perceived to be somehow caught up in and blinded by their daily practice and collective habits, and this perception is used as a means for differentiating the consultants and constructing them as superior. This attribution of elite expert status, with the associated knowledge, objectivity and impartiality, makes it possible for managers at a variety of levels to use consultants as negotiators of conflicting interests and as convincers who can influence different groups and individuals within the organisation. The ways in which the managerial elite does this can be illustrated with an example from the manufacturing company, where one of the executives had a disagreement with the rest of the top management team on a specific issue. In the interview he hinted at how he was planning to in effect use the consultant, for whom he had a lot of respect, as he put it, as an impartial expert to convince himself to go 
along with the rest of the top management team on a decision that he disagreed with. He knew he had probably lost the negotiation anyway, but it was preferable for him to allow himself to be persuaded by the consultant, a highly respected external expert, as opposed to by his fellow team members, particularly the CEO who championed this decision. As this executive predicted, the decision was agreed upon, with his blessing, shortly after the interview. What is interesting about this situation is that the consultant was clearly not impartial in the negotiation and he was not providing expert advice as such, but in essence using his status as an expert to legitimate a particular decision championed by the CEO. Nevertheless, the executive maintained the status of the consultant as a respected expert by whom he could legitimately be convinced. All parties in this particular political negotiation needed and used the consultant in this role as impartial expert to avoid overt and damaging conflict within the executive team.

The examples illustrate how the status of consultants as superior experts is constructed in order and in such a way that specific functions can be performed. The consultants are thus placed 'apart from the common run of mortals' (Mauss, 1972: 37) and the power attributed to them by way of this separateness is the potential ability to produce effects that are perceived as distinct from what even members of the managerial elite can do. Differentiation creates the 'other' who is attributed with a particular kind of expert status by those in relation to whom consultants perform their activities. This attribution of expert status was not just performed by those who had made the decision to hire the consultants, but also by a range of other executives and managers in both organisations. However, it is important to emphasise that consultants are also active agents who position themselves accordingly as elite experts. Both consultants themselves and other social actors take part in creating collectively held definitions, or the 'working consensus' in Goffman's terms (1990), that establish the status and role of consultants. Furthermore, the attribution of status to consultants is situational, as we shall see in the following.

\section{Ambiguity and contestation}

Consultants also face contestation in their interactions with others, although at a different level compared to the Franco-Mauritians. Despite the expectation that consultants possess superior knowledge and expertise, displaying characteristics that others considered excessively intellectual or theoretical often did not go down very well. A middle manager in the manufacturing company for instance described a consultant as 'one of those consultants again... they are so damned knowit-all, right'. One of the executives similarly talked about how he on particular occasions had experienced the consultants as 'too theoretical' and 'flighty'. Thus despite the attribution of expert 
status to the consultants he also expressed a strong sense of ambiguity in relation to their expertise. Consultants should bring something 'new' and provide expertise characterised by superior 'otherness', but such distinction is at the same time easily experienced negatively.

This could also be witnessed openly in meetings where the consultants were in some situations undermined and discredited. For political reasons, it was definitely not always in the interest of all actors in a particular negotiation to maintain the status of consultants. In the manufacturing company, their status was contested with reference to being either too different, i.e. excessively theoretical, not relevant, too 'black and white' etc., or too similar to what 'we' already know. Executives and other managers in private companies are familiar with the management concepts and ideas consultants use, and they belong essentially to the same domain and share the same dominant beliefs. The expertise consultants claim to provide is not in any way protected, demarcated, or otherwise difficult to gain access to; nor is it inherently different from the knowledge of managerial elites. If it sounds too similar to what 'we' already know it is then by implication also not superior.

In the hospital, the social dynamics of contestation differed in some ways. The head surgeons, themselves part of an expert elite but within a different field, were key actors here, and they continually emphasised the lack of validity of the consulting analysis, questioned their findings in meetings and workshops, and worked to undermine and bypass them in other ways as they engaged directly with top hospital management. The head surgeons asserted that the relevant issues and problems had not been thoroughly investigated, and they continually contested the nature of the consultants' expertise, particularly related to technical rationality, to use Weber's term. The consultants tried to maintain their status by comparing their expertise to a doctor's expertise in investigation, diagnosis and cure of illnesses, but from a surgeon's perspective the claimed expertise of consultants to investigate, diagnose and cure organisational 'illnesses' was too unscientific, and thus inferior to their own. Compared to the consultants, the head surgeons saw themselves as more highly educated, as they explicitly stated, and intellectually superior. An element of this contestation was probably indirectly related to resistance to the increasing imposition of dominant neoliberal managerialist ideas and technologies in the public sector, which the presence of the consultants was a part of. Interestingly however, the head surgeons did not so much question these ideas as they contested the consultant's competence in implementing them by correctly and rationally investigating managerial problems and identifying solutions. Rather than contesting their ideas as such, the head surgeons were instead centrally concerned with undermining the consultants for political 
reasons, namely to maintain their power and position within the hospital context by claiming their own management expertise as superior, including in the very management concept the consultants were championing.

\section{Conclusion}

In the analysis of two different types of elites, we have illustrated how elite status is the result of relational and mutually constituting processes of differentiation that produce distinctions and status differences while simultaneously creating the conditions for challenge and contestation. As such we contribute to furthering an understanding of elite formation and maintenance in terms of complex and ambiguous social processes that emerge in relations between groups in particular contexts rather than solely as a result of the agency, power and control over resources exerted by an elite group.

Our analysis of a traditional historically embedded white elite in a post-colonial context and of a modern expert elite representing a hegemonic societal ideology of managerialism and economic efficiency highlights important differences and similarities in the ways in which contestation and attribution operate in the relational constitution of elite status. The FrancoMauritian elite relies strongly on tangible economic assets, such as ownership of land and companies, and their whiteness functions as a visible and symbolically charged source of distinction, in relation to both other (political) elites and non-elites. Attribution, however, is by no means absent. But it is in this case a matter of subtle, perhaps unconscious, social processes of other social groups maintaining and confirming their institutionalised position and symbolic distinction, for instance by showing respect and affording privileges in everyday interaction, through mimicry and entrenched social perceptions of whiteness as desirable - which to a certain extent is difficult to disentangle from the historical legacy of whiteness as evoking fear. Despite expensive cars and smart suits, management consultants by contrast are less visibly and tangibly distinguished and their social position less institutionalised. Setting them apart in interaction requires a more active and explicit drawing of boundaries, particularly when it comes to the knowledge and expertise they rely on as a key source of distinction. This is intangible, and what they do might, as the popular saying goes, be merely a matter of 'the consultant borrowing your watch to tell you the time'. Despite the ideological hegemony of technical rationality, managerialism and the pervasive use of practices of rationalization, 'accountability' and auditing in a wide range of private and public sector contexts (Strathern, 2000), it is not necessarily widely accepted that management consultants' mastery of these ideas and technologies is superior or 
distinct in all relations. Instead, this has to be continuously and explicitly established and symbolically marked in social interaction, and it is therefore also highly situational. Attribution is thus more explicit when it occurs, and separateness appears in some instances as a striking social accomplishment.

Simultaneously, management consultants are more vulnerable and open to contestation in concrete situations of interaction than the Franco-Mauritians. Private property, like land, and control over companies providing employment, is less easily appropriated and/or challenged than the intangible knowledge and expertise of consultants. Nevertheless, owing to the association with colonial injustices, the Franco-Mauritian elite are also - and significantly so - the object of resentment, and their status is contested by other social groups in Mauritius. Such contestation is evident primarily in the political domain where the white privilege of Franco-Mauritians can be used to discredit them and to mobilise support for politicians from other elite groups. In concrete situations of interaction, however, Franco-Mauritians are rarely contested. This indicates that attribution and contestation are closely interlinked, and in the case of the Franco-Mauritian elite both attribution and contestation are more implicit, indirect and overt. Correspondingly, the challenge and contestation of management consultants tend to be as direct and explicit in interaction as attribution.

The attribution of power and status to elites should be understood as resulting from the interactions between widespread beliefs and the agency of both elite groups and other social groups within a particular context. Franco-Mauritians' white skin colour functions as a marker of an elite status in Mauritius, but would not function similarly in societies with majority (or large) white populations, such as in Europe. There, Franco-Mauritians blend in with the majority and their skin colour would function differently, as a source of symbolic distinction, than it does in Mauritius. In the case of management consultants, their status is influenced by the specific organisational contexts where they are performing their activities. In one context they can for instance be attributed with superior objectivity and rationality in contrast to the executives, who see themselves as acting mainly on 'gut feelings', as was perceived in the manufacturing context, while in interaction with head surgeons in the hospital the consultants' abilities to objectively analyse problems and implement rational solutions were instead perceived as inferior. As the specific case illustrated, this was not necessarily because the head surgeons resisted the consultants' managerialist ideas as such. Instead they contested the consultants' mastery of the art of technical rationality, in order to maintain and enhance their own managerial status and 
power in the hospital context - which is comparable to certain examples of Mauritian politicians who refer to criticising Franco-Mauritian privileges in order to enhance their own power.

\section{Contestation and attribution}

In both our cases it is evident that when other social actors or groups do not have an interest in maintaining the status of a particular elite group, it is contested instead. Nevertheless, contestation does not mean that either Franco-Mauritians or management consultants are thereby irrevocably undermined or unmade. In the latter case, although the status of consultants can be contested in one situation, that status might nevertheless be attributed and maintained in another situation, including in contexts such as a public hospital - which resonates with James Scott's (1976) observation that elite values are seldom rejected across the board. At societal level, despite critique, contestation and sometimes ridicule in public discourse, the status of management consultants as an expert elite is maintained. Clients continue to buy their expensive services and the profession continues to grow globally, as do the profits of consulting firms. Hence, it could be argued that attributing elite status and superiority to particular actors or groups serves social and practical purposes in specific contexts and situations. The position of management consultants is continually established because there is a need for the role and functions they can perform in organisations as a result of an ascribed status as superior managerial experts. Their status and power, however, rely more than in the case of the FrancoMauritians on expertise that is particularly valued within a hegemonic ideology of private- and public-sector governance. They are an occupational elite, and thus when they are not within their work environment, either because they leave their consulting career behind or because they find themselves in different non-work contexts, the sources of elite power may diminish accordingly (although their economic privilege might nevertheless be sustained). Conversely, what may explain the stronger contestation in the case of the Franco-Mauritians is that in virtually every context they are perceived as an elite. Owing to the maintenance of their elite position, memories of the injustices of the past continue to shape resentment and contestation. Simultaneously, however, the position of the Franco-Mauritian elite is maintained and confirmed because of the roles and functions they play in providing economic investment and employment in Mauritius. Notwithstanding, then, that both are subject to contestation and attribution, the forms and processes in and through which these manifest are highly situational and context-dependent as a result of the different sources of status and power the two elites posses. 
What we learn from our analysis of these two - at first sight very different - cases is that although elite status depends on the type of elite and the relevant sources of distinction, it is a relational concept, and elites operate, to a large extent, in relation to the (sometimes unknown) expectations of others. These 'others' can be social groups with substantial variety, particularly in the context of diversified societies. This means that we need to question the commonly used dichotomy of elites and subordinates. Elite groups and their status are also constructed in relation to groups with similar status and/or power. In the interaction, the separateness of an elite group is achieved through a relational drawing of boundaries that creates a privileged position, because the elite group is endowed with sources of distinction, power and influence. At the same time however, elites face a perpetual, and at times precarious, tension between contestation and attribution.

Based on our analysis, we argue that attributed status and power plays a more significant role in many cases than is acknowledged - or observed. The task is to study these processes in concrete situations by seeking out the spaces where interaction and encounters take place and where those who occupy particular elite positions are also the objects of categorisation by others. This is not an easy quest, since the often highly ambiguous relationships between an elite group and other social groups tend to complicate a straightforward analysis of the attribution of power and status, especially when it goes hand in hand with some form of often more tangible contestation - which may explain why attribution receives comparatively very little attention in the study of elites. Yet we argue that to understand the position of elites, or inequality for that matter, a fine-grained analysis of how other social actors both make and unmake the position and status of elite groups is required. This emphasises the need for studies focusing on the everyday spheres and particular contexts of different types of elites and their interactions with other social groups, the conditions under which they perform their activities, the way in which they are categorised and positioned by the actors they interact with, and how their status is both attributed and contested in the process.

\section{References}

Alvesson $M$ and Robertson $M(2006)$ The best and the brightest: the construction, significance and effects of elite identities in consulting firms. Organization 13(2): 195-224.

Alvesson M and Empson L (2008) The construction of organizational identity: Comparative case studies of consulting firms. Scandinavian Journal of Management 24: 1-16. 
Armbrüster T (2004) Rationality and its symbols: Signalling effects and subjectification in management consulting. Journal of Management Studies 41(8): 1247-1269.

Bourdieu P (1984 [1979]) Distinction: A Social Critique of the Judgement of Taste. London: Routledge and Kegan Paul.

Bourdieu P (1994) Structures, habitus, power: Basis for a theory of symbolic power. In: Dirks NB, Eley G and Ortner SB (eds) Culture/Power/History: A Reader in Contemporary Social Theory. Princeton, NJ: Princeton University Press, pp. 155-199.

Bourdieu P and Clough LC (1996) The State Nobility: Elite Schools in the Field of Power. Cambridge: Polity Press.

Bourdieu P and Passeron JC (1990) Reproduction in Education, Society and Culture. New York: Sage Publications.

Cohen A (1981) The Politics of Elite Culture: Explorations in the Dramaturgy of Power in a Modern African Society. Berkeley, CA: University of California Press.

Cousin B and Chauvin S (2013) Islanders, immigrants and millionaires: The dynamics of upper-class segregation in St. Barts, French West Indies. In: Hay I (ed) The Geographies of the SuperRich. Northampton, MA: Edward Elgar, pp. 186-200.

Craig D (2005) Rip-off! The Scandalous Inside Story of the Management Consulting Money Machine. London: Original Book Company.

Daloz JP (2007) Elite distinctions: Grand theory and comparative perspectives. Comparative Sociology 6(1/2): 27-74.

Daloz JP (2008) Between majesty and proximity: The enduring ambiguities of political representation in France. French Politics 6(3): 302-320.

Daloz JP (2010) The Sociology of Elite Distinction: From Theoretical to Comparative Perspectives. New York: Palgrave Macmillan.

Davis GF, Yoo M and Baker WE (2003) The small world of the American corporate elite, 19822000. Strategic Organization 1(3): 301-326.

Dogan M (2003) Introduction: Diversity of elite configurations and clusters of power. Comparative Sociology 2(1): 1-15.

Dogan M and Higley J (1998) Elites, Crises, and the Origins of Regimes. Lanham, MD: Rowman and Littlefield.

Eisenlohr P (2006) The politics of diaspora and the morality of secularism: Muslim identities and Islamic authority in Mauritius. Journal of the Royal Anthropological Institute 12(2): 395412. 
Engels F (1968 [1893]) Marx-Engels Correspondence. New York: International Publishers.

Eriksen TH (1998) Common Denominators: Ethnicity, Nation-Building and Compromise in

Mauritius. Oxford: Berg.

Foucault M (1972) The Archeology of Knowledge. New York: Pantheon Books.

Goffman E (1990 [1959]) The Presentation of Self in Everyday Life. London: Penguin Books.

Gramsci A (1971) Selections from the Prison Notebooks. New York: International Publishers.

Harvey P (2002) Elites on the margins: Mestizo traders in the southern Peruvian Andes. In: Shore C

and Nugent S (eds) Elite Cultures: Anthropological Perspectives. London and New York:

Routledge, pp. 74-90.

Hay I (ed) (2013) Geographies of the Super Rich. London: Edward Elgar Books.

Heemskerk E and Fennema M (2009) Network dynamics of the Dutch business elite. International

Sociology 24(6): 807-832.

Ho K (2009) Liquidated: An Ethnography of Wall Street. Durham: Duke University Press.

Jenkins R (2000) Categorization: Identity, social process and epistemology. Current Sociology 48(3):

$7-25$.

Khan SR (2011) Privilege: The Making of an Adolescent Elite at St. Paul's School. Princeton and

Oxford: Princeton University Press.

Khan SR (2012) The Sociology of Elites. Annual Review of Sociology 38: 361-377.

Kärreman D and Alvesson M (2009) Resisting resistance: Counter-resistance, consent and compliance in a consultancy firm. Human Relations 62(8): 1115-1144.

Kihn M (2005) House of Lies. How Management Consultants Steal Your Watch and Then Tell You the

Time. New York: Warner Business Books.

Kovats Beaudoux E and Giraud M (2002) Les Blancs Créoles de la Martinique: Une Minorité

Dominante. Paris: L'Harmattan.

Lamont M, Beljean S and Clair M (2014) What is missing? Cultural processes and causal pathways to inequality. Socio-Economic Review 12(3): 573-608.

Ly-Tio-Fane Pineo H (1993) Ile de France, 1715 - 1746. Mauritius: Mahatma Gandhi Institute.

Marx K (2007 [1867]) Capital: A Critique of Political Economy - The Process of Capitalist

Production. New York: Cosimo Books.

Mauss M (1972) A General Theory of Magic. London: Routledge and Kegan Paul.

McKenna C (2006) The World's Newest Profession: Management Consulting in the Twentieth

Century. Cambridge: Cambridge University Press.

Mills CW (2000 [1956]) The Power Elite. Oxford: Oxford University Press. 
Milner JR's M (2015) Elites: A General Model. Cambridge: Polity Press.

Mizruchi M (2013) The Fracturing of the American Corporate Elite. Cambridge, MA: Harvard

University Press.

Ortner SB (2016) Dark anthropology and its others: Theories since the eighties. Hau: Journal of Ethnographic Theory 6(1): 47-73.

O'Shea J and Madigan C (1997) Dangerous Company: The Consulting Powerhouses and the

Businesses They Save and Ruin. London: Nicholas Brealey Publishing.

Ouroussoff A (2010) Wall Street at War: The Secret Struggle for the Global Economy. Cambridge:

Polity Press.

Pinçon M and Pinçon-Charlot M (1998) Grandes Fortunes: Dynasties Familiales et Formes de

Richesse en France. Paris: Editions Payot et Rivages.

Salverda T (2010) In defence: Elite power. Journal of Political Power 3(3): 385-404.

Salverda T (2011) Embodied signs of elite distinction: Franco-Mauritians' white skin colour in the face of change. Comparative Sociology 10(4): 548-570.

Salverda T (2015) The Franco-Mauritian Elite: Power and Anxiety in the Face of Change. New York: Berghahn Books.

Scott JC (1976) The Moral Economy of the Peasant: Subsistence and Rebellion in Southeast Asia. New Haven: Yale University Press.

Scott JC (1985) Weapons of the Weak: Everyday Forms of Peasant Resistance. New Haven and London: Yale University Press.

Scott J (2008) Modes of power and the re-conceptualization of elites. Sociological Review 56(supplement): $27-43$.

Shore C (2002) Introduction: Towards an anthropology of elites. In: Shore C and Nugent S (eds)

Elite Cultures: Anthropological Perspectives. London and New York: Routledge, pp. 1-21.

Shore C and Nugent S (eds) (2002) Elite Cultures: Anthropological Perspectives. London and New York: Routledge.

Skovgaard-Smith I (2008) Management Consulting in Action - Value Creation and ambiguity in client-consultant relations. Copenhagen: Copenhagen Business School Press.

Skovgaard-Smith I (2013) Management consultants at work with clients: Maintenance and contestation of elite status. In: Abbink J and Salverda T (eds) The Anthropology of Elites: Power, Culture, and the Complexities of Distinction. Palgrave Macmillan: New York, pp. 207226.

Strathern M (2000) Audit Cultures: Anthropological Studies in Accountability, Ethics and 
the Academy. London: Routledge.

Tholstrup S (2005) Konsulenter under luppen. Børsen, 5 August, 2005.

Vaughan M (2005) Creating the Creole Island: Slavery in Eighteenth-Century Mauritius. Durham and London: Duke University Press.

Watson CW (2002) The changing nature of elites in Indonesia today. In: Shore C and Nugent S (eds) Elite Cultures: Anthropological Perspectives. London and New York: Routledge, pp. 110126.

Weber M (1976) The Protestant Ethic and the Spirit of Capitalism. London: Allen and Unwin.

Zald MN and Lounsbury M (2010) The Wizards of Oz: Towards an institutional approach to elites, expertise and command posts. Organization Studies 31(07): 963-996. 